\title{
JA-KO Balinese Pizza: Game Edukasi Interaktif Jaringan Komputer
}

\author{
Putu Trisna Hady Permana $\mathrm{S}^{1}$, I Gede Mahendra Darmawiguna ${ }^{2}$, Made Windu Antara Kesiman ${ }^{3}$ \\ Jurusan Pendidikan Teknik Informatika \\ Universitas Pendidikan Ganesha \\ Singaraja, Bali \\ E-mail: boot.trisna@gmail.com ${ }^{1}$, igd.mahendra.d@gmail.com ${ }^{2}$, dekndu@yahoo.com ${ }^{3}$
}

\begin{abstract}
Abstrak-Pembelajaran yang sering dilakukan saat ini masih terbilang sederhana, dan sangat jarang menggunakan sarana pembelajaran berbasis teknologi, sehingga para peserta didik tidak tertarik untuk belajar dan membuat pemahaman mereka pada materi pelajaran tersebut menjadi kurang. Jaringan komputer merupakan salah satu materi pelajaran teknologi informasi dan komunikasi yang biasanya masih sulit untuk dipahami apabila hanya menggunakan pembelajaran sederhana. Game edukasi adalah salah satu sarana pembelajaran yang dapat membuat para peserta didik tertarik untuk belajar dan membantu mereka dalam memahami materi pelajaran khususnya materi pelajaran jaringan komputer karena selain belajar mereka juga akan diajak bermain. Metode penelitian yang digunakan adalah penelitian dan pengembangan (research and development), bertujuan untuk mengembangkan multimedia pembelajaran interaktif berbasis game edukasi dengan model instructional games pada materi jaringan komputer. Game edukasi ini memuat materi jaringan komputer, dimana pengguna game ini akan diajak menyelesaikan misi sebagai pegawai pizza seperti membuat pizza dan mengirim pizza. Hasil penelitian ini berupa multimedia pembelajaran interaktif berbasis game edukasi yang dapat digunakan sebagai sarana pembelajaran di sekolah maupun di luar sekolah, khususnya pada materi jaringan komputer.
\end{abstract}

Kata Kunci-Game Edukasi, Multimedia Pembelajaran Interaktif, Jaringan Komputer, Model Instructional Games, Sarana Pembelajaran.

Abstract-Learning process is usually done in simple way, and seldom use the technology-based learning tools, so that student are not interested in learning and make their understanding on theparticular subjects became less. Computer network isa subjects in information and communication technology course that usually difficult to understand if only use a simple learning way. Educational game is one of the learning tools that can make the students interested in learning and help them to understand the of computer network subject in particular because in addition to learning they would also be invited to play. The research method used is the research and development $(R \& B)$, aims to develop an interactive learning multimedia based educational games with instructional games model on the subject of computer network. The educational game contains matter of computer network, where users will be invited to complete the game's mission as an employee of pizza like making pizza and sending pizza. The results of this study are interactive learning multimedia based on educational game that can be used as a tools of learning in school and outside school, especially on the matter of computer networks.

Keywords-Educational Games, Multimedia Interactive Learning, Networking Computers, Instructional Games Model, Leaning Tools.

\section{PENDAHULUAN}

Perkembangan teknologi informasi dan komunikasi saat ini membawa dampak yang sangat besar pada berbagai bidang kehidupan, salah satunya yaitu bidang pendidikan. Pada proses pembelajaran, komputer telah dilibatkan sebagai alat bantu dalam proses pembelajaran. Saat ini telah berkembang media pembelajaran dengan bantuan komputer hampir dalam setiap mata pelajaran.

Multimedia Pembelajaran Interaktif merupakan salah satu jenis media pembelajaran dengan bantuan komputer yang saat ini telah banyak digunakan oleh para pengajar dalam proses pembelajaran.Penggunaan multimedia pembelajaran interaktif tersebut akan lebih menarik minat belajar para peserta didik apabila berbasis game yang bersifat edukasi. Model instructional gamesmerupakan model yang cocok digunakan untuk pengembangan sebuah game edukasi karena menyediakan suasana yang memberikan fasilitas belajar yang menambah kemampuan dan menyediakan tantangan yang menyenangkan bagi peserta didik [4]. 
Dalam dunia pendidikan saat ini masih banyak materi pelajaran yang bersifat abstrak seperti materi jaringan komputer sehingga peserta didik mengalami kesulitan untuk memahami materi pelajaran jika hanya dibelajarkan dengan cara tradisional tanpa menggunakan media penunjang. Yang maksud abstrak dalam konteks ini yaitu materi pelajaran yang diterangkan hanya sekedar pengertian saja sehingga membuat para peserta didik sulit untuk memahami isi dari materi yang dipelajari. Oleh karena itu disusunlah suatu program aplikasi multimedia pembelajaran model instructional games berbasis game edukasi pada mata pelajaran TI dengan materi jaringan komputer yaitu mengenai pengertian jaringan, konsep jaringan, dan jenis-jenis jaringan dengan harapan dapat menarik perhatian dan mempermudah pengertian para peserta didik, dalam mempelajari jaringan teknologi informasi dan komunikasi.

\section{KAJIAN TEORI}

\section{A. Multimedia Interaktif}

Multimedia pembelajaran interaktif bisa diartikan sebagai penggunaan berbagai media, termasuk di dalamnya teks, gambar, video, suara dan animasi, yang membawa pesan-pesan atau informasi dengan tujuan pembelajaran atau bersifat instruksional yang disampaikan dan ditampilkan dengan menggunakan bantuan komputer secara saling aktif untuk memberikan kemudahan dalam menampilkannya dan menyampaikan pesan didalamnya.

Penggunaan media pembelajaran dalam proses belajar mengajar dapat membangkitkan keinginan dan minat yang baru, membangkitkan motivasi dan rangsangan kegiatan belajar, dan bahkan membawa pengaruh-pengaruh psikologis terhadap siswa [1]. Selain membangkitkan motivasi dan minat siswa, media pembelajaran juga dapat membantu siswa meningkatkan pemahaman, menyajikan data dengan menarik dan terpercaya, memudahkan penafsiran data, dan memadatkan informasi [1].

Secara umum manfaat yang dapat diperoleh dalam penggunaan multimedia pembelajaran interaktif adalah proses pembelajaran lebih menarik, lebih interaktif, jumlah waktu mengajar dapat dikurangi, kualitas belajar siswa dapat ditingkatkan dan proses belajar mengajar dapat dilakukan dimana dan kapan saja, serta sikap belajar siswa dapat ditingkatkan.

\section{B. Model Instructional Games}

Instructional games merupakan perangkat lunak yang didesain untuk meningkatkan motivasi dengan menambahkan aturan permainan atau kompetisi dalam aktivitas pembelajaran. Instructional games menyediakan lingkungan menarik dimana siswa harus mengikuti aturan yang telah diberikan sebelumnya untuk mencapai tujuan. Ketika siswa mengetahui bahwa mereka akan bermain game, mereka mengharapkan sebuah aktivitas yang menyenangkan dan menghibur dikarenakan adanya sebuah tantangan dari sebuah kompetisi dan adanya potensi untuk memenangkannya.

Tujuan Model Instructional Games adalah untuk menyediakan pengalaman belajar yang memberikan fasilitas belajar untuk menambah kemampuan siswa melalui bentuk permainan mendidik [5]. Model Instructional Games tidak perlu menirukan realita namun dapat memiliki karakter yang menyediakan tantangan yang menyenangkan bagi siswa.

Instructional games dapat terlihat dengan mengenali pola pembelajaran melalui permainan yang dirancang sedemikian rupa, sehingga pembelajaran lebih menantang dan menyenangkan [5]. Program permainan yang dirancang baik dapat memotivasi siswa dan meningkatkan pengetahuan dan keterampilannya [1].

\section{Game}

Game merupakan sebuah permainan yang menarik dan menyenangkan. Game adalah salah satu mesin cerdas dalam budaya masyarakat kontemporer [3]. Game yang ada sekarang memiliki berbagai macam jenis atau yang dikenal dengan istilah genre. Salah satunya game yang bergenre edukasi.

Game bergenre edukasi ini bertujuan untuk memancing minat belajar anak terhadap materi pelajaran sambil bermain. Sehingga dengan perasaan senang diharapkan anak bisa lebih mudah memahami materi pelajaran yang disajikan. Genre ini sebenarnya lebih mengacu kepada isi dan tujuan game, bukan genre yang sesungguhnya.

\section{Jaringan Komputer}

Jaringan komputer adalah kumpulan sejumlah peripheral yang terdiri dari beberapa komputer, printer, LAN card, dan peralatan lain yang dapat saling terintegrasi satu sama lain [2]. Banyak sekali manfaat yang dapat kita peroleh apabila komputer kita terhubung dengan jaringan,.diantaranya :

\section{Sharing resources}

2. Media Komunikasi 
3. Integrasi Data

4. Pengembangan dan Pemeliharaan

5. Keamanan Data

6. Sumber Daya Lebih Efisien dan Informasi Terkini.

Agar kita tidak menemui banyak kesulitan saat membuat jaringan pada suatu sistem operasi, maka ada beberapa model jaringan komputer setidaknya harus kita pahami. Arsitektur fisik jaringan identik dengan topologi yang akan digunakan dalam jaringan tersebut [2]. Hal tersebut bertujuan, agar apabila suatu saat jaringan tersebut ingin kita kembangkan menjadi suatu jaringan dengan skala yang lebih besar dan luas maka pemasangan maupun perawatan jaringan menjadi lebih mudah.

\section{E. Adobe Flash}

Perangkat lunak Adobe Flash yang selanjutnya disebut flash, dulunya bernama "macromedia flash" merupakan software multimedia unggulan yang dulunya dikembangkan oleh macromedia, tetapi sekarang dikembangkan dan di distribusikan oleh Adobe Sistem. Sejak tahun 1996, flash menjadi populer untuk menambahkan animasi dan interaktif website. Flash biasanya digunakan untuk membuat animasi, hiburan dan berbagai komponen web, diintegrasikan dengan video dalam halaman web sehingga dapat menjadi aplikasi munlimedia yang kaya.

\section{METODOLOGI}

\section{A. Analisis Perangkat Lunak}

\section{1 ) Kebutuhan Perangkat Lunak}

Game edukasi ini didalamnya tidak hanya menyediakan permainan semata namun menyediakan juga media pembelajaran berupa kumpulan materi jaringan yang dapat dipelajari sebelum memulai bermain. Pada setiap game yang dimainkan juga akan terdapat unsur pelajaran dengan materi jaringan komputer yang akan dimasukan kedalamnya sehingga dalam mempelajari materi jaringan komputer akan menjadi lebih menarik dan menyenangkan.

\section{2) Tujuan Pengembangan Perangkat Lunak}

Tujuan dari pengembangan perangkat lunak ini adalah mengembangkan sebuah multimedia pembelajaran interaktif berbasis game edukasi dimana didalamnya terdapat materi pelajaran jaringan komputer. Dalam game edukasi tersebut tidak hanya menonjolkan permainan saja namun cenderung pada penyajian materi pelajaran jaringan komputer yaitu mengenai pengertian jaringan, perangkat jaringan, dan jenis-jenis jaringan, yang dikombinasikan dengan game yang mengasikkan.

\section{3) Masukan dan Keluaran Perangkat Lunak}

1. Masukan: Dalam perangkat lunak multimedia pembelajaran interaktif berbasis game edukasi ini berupa nama pemain.

2. Keluaran: dari perangkat lunak ini adalah game edukasi JA-KO Balinese Pizza. Dimana pada game edukasi ini pemain akan ditugaskan selayaknya pegawai pizza mulai dari membaca buku resep, membuat pizza, dan kemudian mengantarkannya kepada para pelanggan.

\section{4) Model Fungsional Perangkat Lunak}

Berdasarkan analisis sistem yang telah dilakukan maka digunakanlah flowchart untuk mendeskripsikan alur proses permainan yang menggambarkan hubungan antara pengguna dengan perangkat lunak game edukasi.

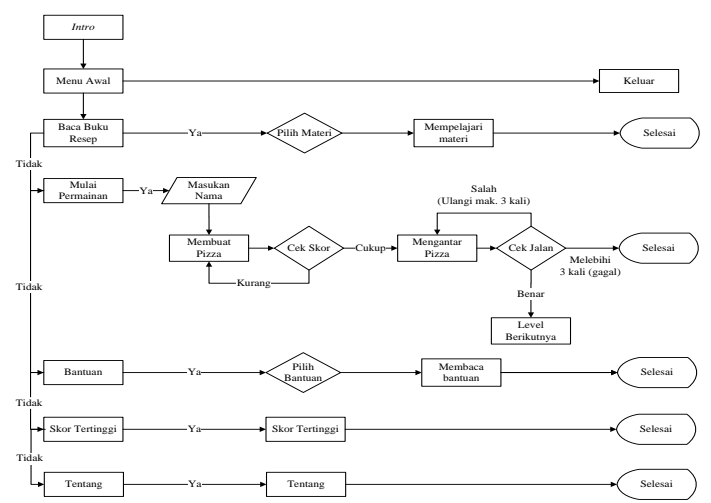

Gambar 1 :Flowchart Game Edukasi JA-KO Balinese Pizza

\section{B. Perancangan Perangkat Lunak}

Tahap perancangan perangkat lunak adalah tahap selanjutnya setelah melakukan analisis perangkat lunak. Rancangan perangkat lunak yang dibuat bersifat user friendly agar pengguna merasa nyaman dan mudah untuk menggunakannya.

\section{1) Batasan Perancangan Perangkat Lunak}

Adapun batasan perancangan perangkat lunak game edukasi JA-KO Balinese Pizza dapat dipaparkan sebagai berikut. 
- Pengguna tidak dapat menambahkan materi jaringan komputer kedalam buku resep.

- Pengguna tidak dapat memilih, menambahkan, ataupun mengganti pertanyaan pada permainan membuat pizza.

- Pengguna tidak dapat membuat jalan lain selain jalan yang telah disediakan untuk disusun.

2) Perancangan Struktur Menu Perangkat Lunak

Perancangan struktur menu perangkat lunak ini terdiri dari beberapa komponen. Dimulai dari intro game yang kemudian dilanjutkan dengan keadaan menu awal yang terdiri dari beberapa pilihan menu yaitu membaca buku resep, mulai permainan, tentang, skor tertinggi, bantuan, dan keluar.

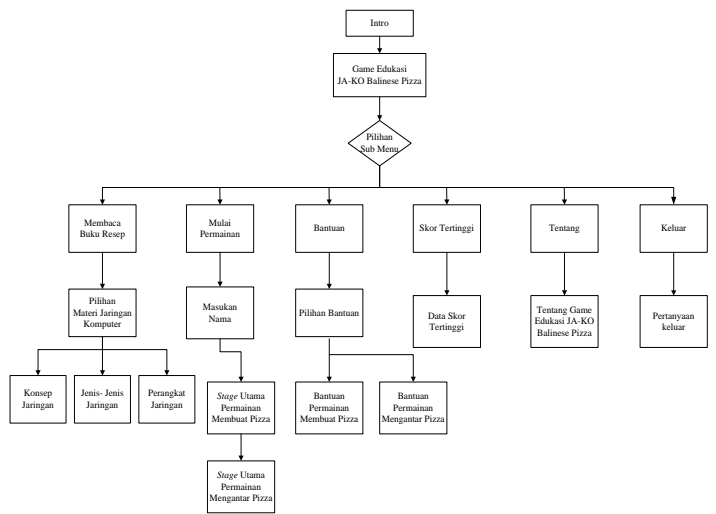

Gambar 2 :Perancangan Struktur Menu Game Edukasi JA-KO Balinese Pizza

3) Perancangan Antarmuka Perangkat Lunak

Perancangan antarmuka perangkat lunak merupakan proses pembuatan antarmuka yang akan digunakan untuk berinteraksi antara pengguna dengan perangkat lunak. Rancangan yang dibuat bersifat user friendly dimana bertujuan agar pengguna merasa tertarik, nyaman, dan mudah dalam menggunakannya. Beberapa rancangan antarmuka perangkat lunak ini dituangkan dalam bentuk storyboard seperti berikut.
- Storyboard Tampilan Menu Awal

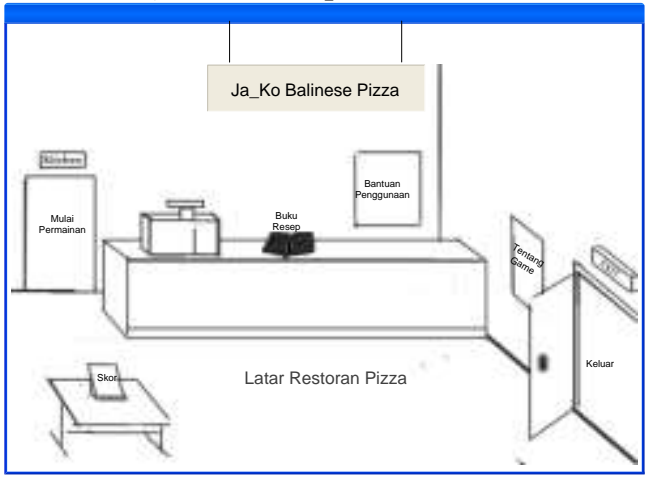

Gambar 3 : Tampilan Menu Awal

\section{Keterangan}

- Terdapat backsound Rindik saat berada pada menu awal.

- Terdapat suara selamat datang dari karakter.

- Storyboard Tampilan Buku Resep

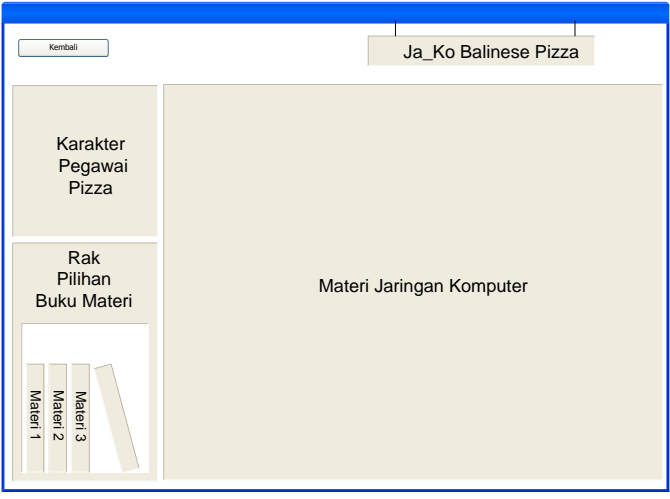

Gambar 4 : Tampilan Buku Resep

\section{Keterangan}

- Terdapat backsound Rindik saat berada pada menu buku resep.

- Terdapat suara penjelasan dari karakter. 
- Storyboard Tampilan Permainan Membuat Pizza

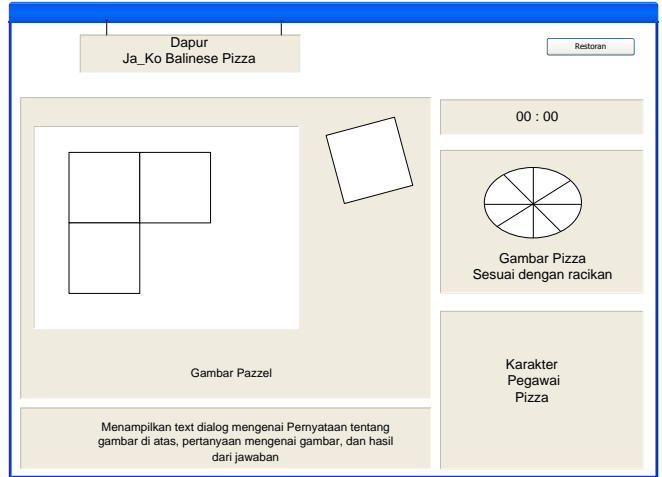

Gambar 5 : Tampilan Permainan Membuat Pizza

\section{Keterangan}

- Terdapat backsound Rindik saat berada pada permainan membuat pizza.

- Storyboard Tampilan Permainan Mengirim Pizza

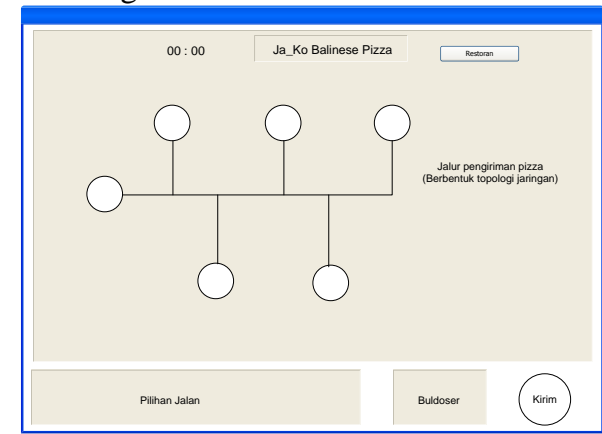

Gambar 6 : Tampilan Permainan Mengirim Pizza

\section{Keterangan}

- Terdapat backsound Rindik saat berada pada permainan mengirim pizza.

\section{PEMBAHASAN}

\section{A. Implementasi Perangkat Lunak}

Pada tahap implementasi perangkat lunak akan dipaparkan beberapa hal yang berkaitan dengan implementasi perangkat lunak, yaitu lingkungan implementasi perangkat lunak, batasan implementasi perangkat lunak, implementasi struktur data perangkat lunak serta implementasi layar antarmuka perangkat lunak.

\section{1) Lingkungan Implementasi Perangkat Lunak}

Lingkungan implementasi perangkat lunak game edukasi JA-KO Balinese Pizza menggunakan beberapa perangkat lunak dan perangkat keras sebagai berikut.
- Spesifikasi Perangkat Lunak
a. Sistem Operasi Microsoft Windows 8 Pro
b. Adobe Flash Profesional CS.5
c. Adobe Illustrator CS.6
d. Adobe Photoshop CS.3
e. Sound Forge 9.0

- Spesifikasi Perangkat Keras
a. Laptop Compaq Presario CQ40
b. Intel ${ }^{\circledR}$ Core $^{\mathrm{TM}} 2$ Duo CPU T6400 @2.00GHz 2.00GHz
c. RAM 3.00 GB DDR3
d. Harddisk $200 \mathrm{~GB}$
e. Dilengkapi alat input dan output

2) Batasan Implementasi Perangkat Lunak

Batasan implementasi perangkat lunak game edukasi JA-KO Balinese Pizza dapat dipaparkan sebagai berikut.

- Pengguna tidak dapat menambahkan materi jaringan komputer kedalam buku resep yang terdapat dalam game.

- Pengguna tidak dapat memilih, menambahkan, ataupun mengganti pertanyaan pada permainan membuat pizza.

- Pengguna tidak dapat membuat jalan lain selain jalan yang telah disediakan untuk disusun oleh game.

3) Implementasi Struktur Menu Perangkat Lunak

Pada tahap implementasi struktur menu perangkat lunak ini terdapat 6 komponen menu pada menu awal. Setelah intro game, akan muncul menu awal dimana pada menu awal ini terdapat 6 menu untuk menuju tampilan menu berikutnya yaitu tampilan membaca buku resep, tampilan mulai permainan, tampilan tentang game, tampilan skor tertinggi, tampilan bantuan,dan keluar.Selanjutnya dalam menu buku resep terdapat tampilan pilihan buku resep yang terdiri dari tiga pilihan yaitu buku konsep jaringan, jenis - jenis jaringan, dan perangkat jaringan, dalam menu mulai permainan terdapat tampilan masukan nama yang kemudian dilanjutkan stage utama permainan membuat dan mengirim pizza, dalam menu bantuan terdapat tampilan pilihan bantuan yaitu bantuan membuat pizza dan bantuan mengirim pizza, dalam menu data skor terdapat data dari peraih skor tertinggi 
tertinggi, dalam menu tentang game terdapat gambaran tentang game edukasi, dan dalam menu keluar terdapat pertanyaan keluar.

4) Implementasi Layar Antarmuka Perangkat Lunak

Pada tahap implementasi layar antarmuka perangkat lunak akan dipaparkan mengenai tampilan - tampilan antarmuka dari game edukasi JA-KO Balinese Pizza berdasarkan storyboard. Beberapa tampilan antarmuka game edukasi JA-KO Balinese Pizza sebagai berikut.

- Implementasi Karakter Pegawai JA-KO Balinese Pizza

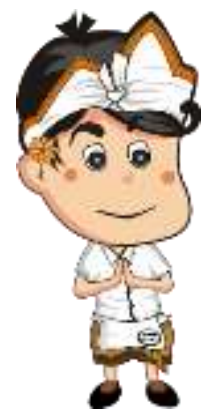

Gambar 7 : Implementasi Karakter Pegawai JA$\mathrm{KO}$

- Implementasi Menu Awal

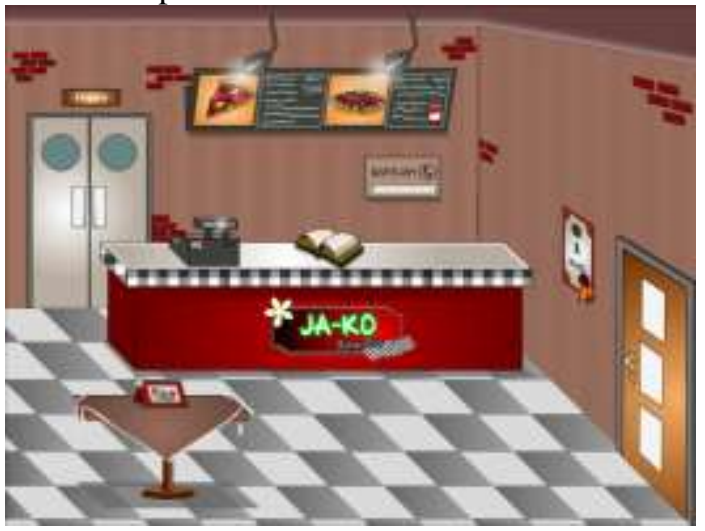

Gambar 8 : Implementasi Menu Awal
- Implementasi Buku Resep

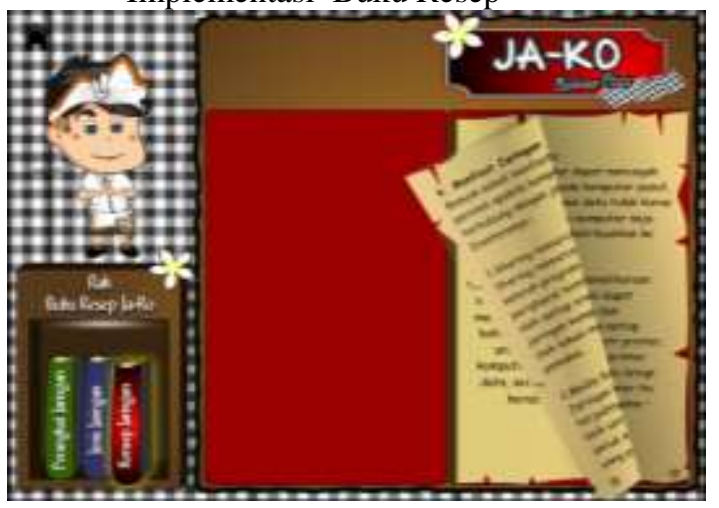

Gambar 9 : Implementasi Buku Resep

- Implementasi Permainan Membuat Pizza

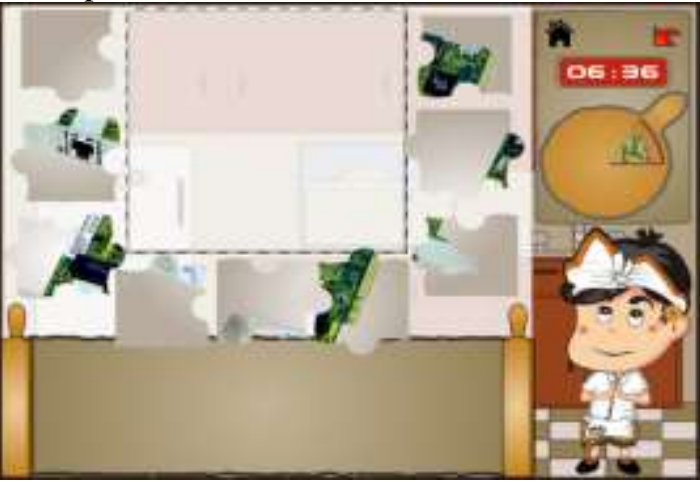

Gambar 10 : Implementasi Permainan Membuat Pizza

- Implementasi Permainan Mengirim Pizza

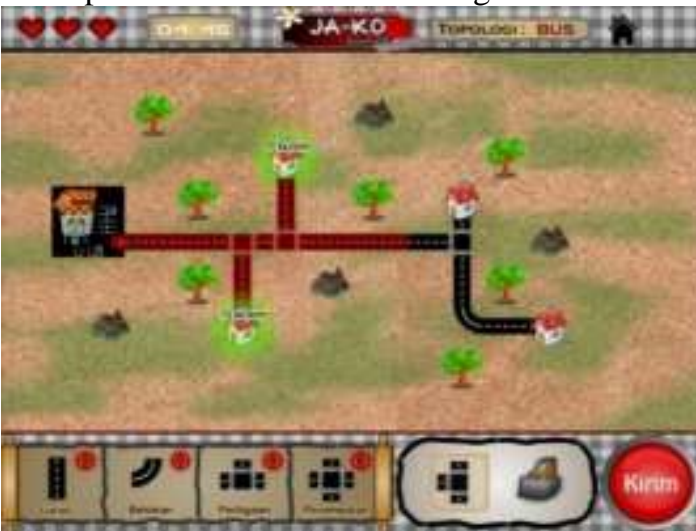

Gambar 11 : Implementasi Permainan Mengirim Pizza Level 1 Topologi Bus

\section{5) Alur Permainan}

Permainan pada game JA-KO Balinese Pizza akan disimulasikan selayaknya pekerjaan dari pegawai pizza, dimulai dari membaca buku resep pembuatan pizza yang padagame akan berisi materi pelajaranjaringan komputer mulai dari pengertian sampai 
dengan topologi jaringan, setelah selesai mempelajarinya akan dilanjutkan dengan meracik bahan untuk membuat pizza dimana bahan tersebut bukanlah bahan pizza sesungguhnya namun suatu pertanyaan dari gambar yang ada mengenai komponen jaringan komputer dimana terlebih dahulu pemain akan diminta untuk menyusun potongan-potongan gambar agar menjadi gambar yang utuh. Terakhir yaitu proses pengiriman pizza kerumah pelanggan, dimana restoran pizza dianggap sebagai sebuah server dan rumah-rumah pelanggan adalah client nya, yang mana dalam proses pengiriman pizza harus mengikuti aturan seperti layaknya topologi jaringan komputer. Untuk tugas membuat pizza akan digunakan game puzzel, dimana pada game ini pemain diharuskan menyusun puzzel yang ada terlebih dahulu untuk memperoleh pertanyaan. Setiap pertanyaan yang terjawab benar akan terbentuk satu potong pizza. Pemain harus dapat menjawab benar minimal 4 pertanyaan untuk melanjutkan ke permainan mengirim pizza. Pada permainan membuat pizza ini akan disediakan 6 level pertanyaan dan sejumlah waktu untuk melaksanakan tugas membuat pizza. Setelah sukses dalam membuat pizza pemain akan ditugaskan untuk mengirim pizza tersebut kepara pelanggan. Dalam tugas mengirim ini akan digunakan game menyusun jalan, dimana akan disediakan sejumlah jalan untuk disusun sesuai dengan topologi jaringan yang tugaskan seperti topologi bus, ring star, mesh dan tree. Pada permainan menyusun jalan ini akan disediakan 10 level permainan yang akan diacak dan juga sejumlah waktu untuk menyusun jalan tersebut.

\section{B. Pengujian Perangkat Lunak}

Tahap selanjutnya setelah implementasi perangkat lunak adalah tahap pengujian perangkat lunak. Pada tahap pengujian ini akan dipaparkan mengenai tujuan pengujian perangkat lunak, pelaksanaan pengujian perangkat lunak serta evaluasi dari pengujian perangkat lunak

\section{1) Tujuan Pengujian Perangkat Lunak}

Pengujian perangkat lunak game edukasi JAKO Balinese Pizza dilakukan dengan mempergunakan pengujian blackbox testing. Dimana pengujian ini hanya dilihat berdasarkan keluaran yang dihasilkan dari data atau kondisi masukan yang diberikan untuk fungsi yang terdapat pada perangkat lunak tanpa melihat bagaimana proses untuk mendapatkan keluaran. Tujuan pengujian game edukasi JA-KO Balinese Pizza adalah untuk.

- Menguji kebenaran alur game berdasarkan storyboard.

- Mengetahui kebenaran semua tombol navigasi dan penggunaan kursor yang terdapat pada game.

- Menguji penggunaan game edukasi JAKO Balinese Pizza pada lima orang dengan menggunakan hardware mereka masing-masing.

\section{2) Pelaksanaan Pengujian Perangkat Lunak}

Berdasarkan perancangan pengujian perangkat lunak di atas, maka pengujian game edukasi JA-KO Balinese Pizza dilakukan oleh: 1. Pengembang untuk pengujian kesesuai game; 2. Lima orang pemain yang diambil secara acak, yaitu dua siswa kelas XI SMAN 1 Singaraja dan tiga siswa kelas X SMAN 1 Sukasada. Pengujian dilakukan sesuai dengan kasus uji yang telah dirancang sebelumnya dengan menggunakan tiga jenis angket yaitu:

- Angket kesesuaian alur game dengan storyboard

- Angket kesesuaian tombol navigasi dan penggunaan kursor.

- Angket penggunaan Game Edukasi JAKO Balinese Pizza.

\section{3) Evaluasi Hasil Pengujian Perangkat Lunak}

Berdasarkan hasil pengujian melalui angket kesesuaian alur game dengan storyboard diketahui bahwa proses alur game telah sesuai dengan storyboard yang telah dibuat sebelumnya. Semua alur game mulai dari saat pertama kali game dijalankan sampai dengan selesai melakukan pekerjaan mengirim pizza dan kemudian keluar dari game sesuai dengan storyboard.

Berdasarkan hasil pengujian melalui angket kesesuaian tombol navigasi dan penggunaan kursor diketahui bahwa semua fungsi tombol navigasi pada setiap menu yang terdapat dalam game telah berfungsi dengan baik dan sesuai dengan storyboard yang telah dibuat.

Berdasarkan hasil pengujian melalui angket penggunaan game edukasi diketahui bahwa 
perangkat lunak game edukasi JA-KO Balinese Pizza sudah berjalan sesuai prosedur setelah dimainkan oleh lima orang yang berbeda pada perangkat keras mereka masing -masing. Alur game sesuai dengan storyboard yang telah dibuat dan juga kualitas gambar, suara yang dihasilkan, dan animasi yang terdapat pada game bagus. Selain itu dari evaluasi angket,game edukasi JA-KO Balinese Pizza cukup mudah untuk digunakan, kualitas game yang dihasilkan bagus, dan game sangat sesuai digunakan sebagai media pembelajaran dengan materi jaringan komputer.

\section{KESIMPULAN}

Berdasarkan penelitian dan pengembangan multimedia pembelajaran interaktif model instructional games berbasis game edukasi jaringan komputer, dapat ditarik kesimpulan sebagai berikut.

1. Game edukasi JA-KO Balinese Pizza ini sudah berjalan dengan baik. Game edukasi JA-KO Balinese Pizza merupakan multimedia pembelajaran dengan model instructional games yang dapat digunakan sebagai sarana pembelajaran untuk menarik minat belajar dan mendukung proses pembelajaran khususnya pada materi jaringan komputer disekolah maupun luar sekolah, sehingga materi jaringan komputer tidak lagi akan terlihat abstrak dan sulit untuk dipahami oleh para peserta didik.

2. Dalam pengembangan game edukasi JA-KO Balinese Pizza selanjutnya diharapkan dapat mengembangkannya dengan menggunakan animasi 3 dimensi atau pada platform Android karena pada game ini masih menggunakan animasi 2 dimensi dan dikembangkan dengan Adobe Flash.Materi yang disajikan pada game JA-KO Balinese Pizza versi 1.0 hanya materi jaringan komputer saja dengan model instructional games, untuk kedepan pada versi selanjutnya materi yang disajikan dapat berupa materi materi lainya dengan model pembelajaran lainnya, dimana masih banyak terdapat materi pelajaran yang sulit untuk dipahami.Konsep yang digunakan pada game ini hanya terdapat 2 misi permainan, untuk pengembangan selanjutnya diharapkan misi permainannya ditambahkan.

\section{REFERENSI}

[1] Arsyad, A. 2007. Media Pembelajaran. Jakarta: PT. Raja Grafindo Persada.

[2] Kurniawan, W. 2007. Jaringan Komputer. Yogyakarta: Andi.

[3] Lakoro, R. 2009. Mempertimbangkan Peran Permainan Edukasi dalam Pendidikan di Indonesia. Artikel. Tersedia pada http://www.its.ac.id/ personal/files/pub/3735-

ramokmempertimbangkan\%20game\%20edukasi. pdf. Diakses tanggal 5 Juni 2012.

[4] Mulyadi, A. W. 2010. Pengembangan Multimedia Pembelajaran Interaktif CAI Model Instructional Games untuk Meningkatkan Motivasi Belajar Siswa. Skripsi (tidak diterbitkan). Tersedia pada http://cs.upi.edu/uploads/paper_

skripsi_dik/Paper_ahmad_wisnu.pdf. Diakses tanggal 5 Mei 2012.

[5] Rusman. 2011. Model-Model Pembelajaran Mengembangkan Profesionalisme Guru. Jakarta: PT. RajaGrafindo Persada. 